\title{
A Note on Stereoscopic Photography
}

\author{
By Dr. John R. Baker, Department of Zoology and Comparative Anatomy, Oxford
}

$\mathbf{I}^{\mathrm{T}}$ is sometimes stated that in the stereoscopic photography of near objects it makes no difference at all to the images whether the cameras are placed parallel to one another, or convergent upon the object.

In Fig. 1 the object to be photographed has three distinct points upon it, $A, B$ and $C$. The thick black

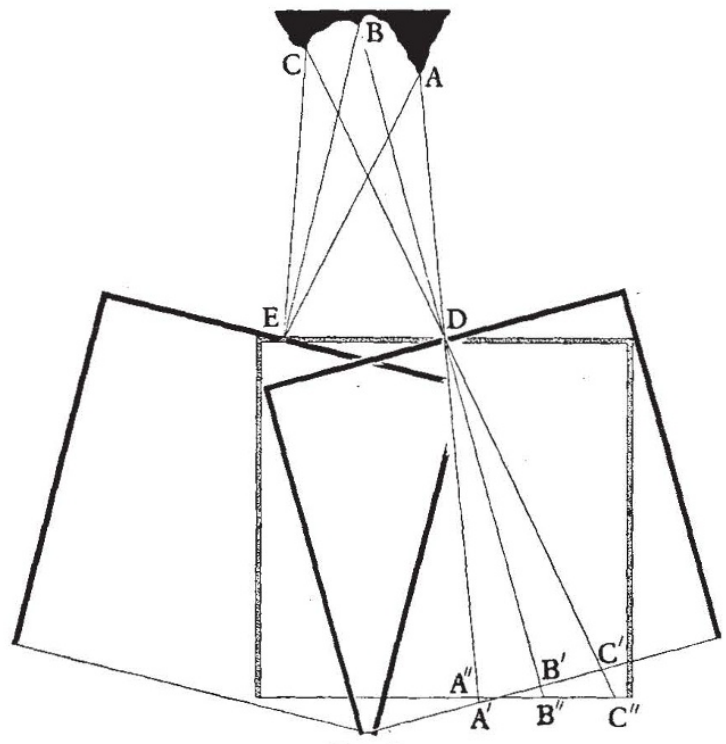

FIG. 1.

lines indicate the outlines of the camera in its two positions for obtaining convergent views of the object. (The angle of convergence shown in Fig. 1 is purposely made greater than the greatest angle of convergence possible with normal vision, so as to exaggerate the point that is to be made.) An exactly similar camera is also shown in the position it would occupy for the right-eye view, if photographs were going to be taken with parallel cameras. The outline of this camera is indicated by dots between lines. For the sake of simplicity pin-hole cameras are represented. The apertures of both pairs of cameras are at $D$ for the right-eye view and at $E$ for the lefteye view.

The right-eye convergent camera produces images of the points $A, B$ and $C$ at $A^{\prime}, B^{\prime}$ and $C^{\prime}$. The righteye parallel camera produces the images at $A^{\prime \prime}, B^{\prime \prime}$ and $C^{\prime \prime}$. Now $A^{\prime} B^{\prime}$ exactly equals $B^{\prime} C^{\prime}$, while $A^{\prime \prime} B^{\prime \prime}$ is less than $B^{\prime \prime} C^{\prime \prime}$. Therefore the view obtained with the convergent camera is not the same as that obtained with the parallel camera.

Which is the proper position of the camera for the representation of normal binocular vision as closely as possible ? Imagine an eye situated at $D$. The owner of the eye would notice that the angle subtended between $A$ and $B$ was exactly equal to the angle sub. tended between $B$ and $C$. In making an accurate drawing of the appearance of the object from his viewpoint, he would therefore make $A B$ exactly equal to $B C$ on his sheet of paper. This is what the convergent camera does. The convergent camera therefore gives the proper representation of the object.

The parallel camera has the advantage of giving a larger field of view in focus at the same time, if lenses of wide aperture are used and if the object presents a more or less flat surface at right angles to the axis of the cameras; but its image is not absolutely accurate. It must be remembered that in stereoscopic photography one is relying for one's effects upon minute differences between the two prints, and extreme accuracy is therefore important if a truthful appearance is to be given.

The facts stated in this note give support to the tilting-stage method of stereo-photomicrography, for in this method the two views are convergent. The other method, in which the object is photographed first at one side of the field of view and then at the other, and the two photographs treated as a stereoscopic pair, is equivalent to the use of parallel cameras.

\section{International Co-operation in Astronomy}

$\mathrm{T}$ HE International Astronomical Union held its fifth general assembly at Paris on July 10-17, at the Centre Marcelin Berthelot, when nearly three hundred astronomers were gathered together from twenty-seven different countries. The President of the French Republic was present at the opening ceremony, when addresses of welcome were given by the Minister of Public Instruction, the president of the French National Committee of Astronomy (M. de la Baume Pluvinel), the director of the Paris Observatory (M. Esclangon) and replied to by the president of the Union, Prof. F. Schlesinger. During the meeting the adhesion of three new countries,
U.S.S.R., China and Yugoslavia, was announced; with the growing number of countries supporting the Union it was found possible substantially to reduce the unit of subscription from the different countries, without hindering the work which the Union has already undertaken to support.

A great part of the value of the meeting lies in the informal discussions between small groups which were possible at some of the social gatherings organised by the generously hospitable French hosts, such as the visits to the observatories at Meudon and Paris. But the work of the Union is done mainly at the meetings of thirty-one committees which 
examine schemes of co-operative work in the different branches of astronomy. One of the features of the present meeting was the number of joint meetings of commissions, which after dealing with their own special work, discussed jointly borderline problems where their common interests were concerned. Thus the commissions on ephemerides, meridian astronomy, and the movements and positions of planets, asteroids and satellites combined to discuss and press for further experimental work-to be followed later by international co-operation schemes for the determination of systematic corrections to star positions from observations of minor planets. To the commissions on notations and ephemerides were referred two resolutions on the symbols at present in use for time, which had been sent in by two national committees on astronomy. They recommended, and the Union adopted their point of view, that the symbol G.C.T. for Greenwich mean time reckoned from midnight should be dropped and that the symbol U.T. (Universal Time) should be used instead.

A move of the Bureau of Latitude Variation from Mizusawa to Naples on the coming retirement of Dr. Kimura was decided upon. Special tributes were paid to Kimura's work and he was made a Président d'Honneur of the commission on latitude, a similar compliment being paid to Sir Frank Dyson by the commission on meridian astronomy. The commission on spectrophotometry directed attention to the fundamental importance of producing photographic plates of uniform sensitivity over the surface, and urged further work on this point at the research laboratories of the various plate manufacturers. The physical study of comets was removed from the commission on planets and satellites, and in a general rearrangement of subjects the zodiacal light, the night sky and related subjects were grouped with meteoric astronomy, while novæ were given a special sub-commission in the commission on stellar spectra. The commission on lunar nomenclature, which has completed its work and published a map of the moon with a list of lunar formations, has been replaced by a new commission on the moon to deal also with occultations and physical researches.
Among the resolutions adopted on the recommenda. tions of the committee on stellar statistics we may mention a definite choice of the galactic pole at $\alpha=12^{\mathrm{h}} 40^{\mathrm{m}}, \delta=+28^{\circ}(1900 \cdot 0)$, the position used in Ohlsson's tables of galactic co-ordinates. In solar physics resolutions were adopted for co-operative work on line profiles, for the publication of character. istic solar numbers of the sun separately for the four quadrants, N.E., N.W., S.E. and S.W., and for observations of active prominences at short intervals by a number of different methods. A number of technical resolutions on star positions cannot very well be given here but mention may be made of a resolution to issue a supplementary list of observatories and astronomers, of alterations in the cipher code for astronomical telegrams and of a preliminary list of notations prepared by Prof. Strömgren, the president of the commission on notations, and left until the next general assembly for further discussion and examination by those interested.

The volume of draft reports prepared by the presidents of commissions, well above two hundred pages in length, contains much valuable work but can be left over for review when the complete volume is printed.

One feature of great value at the meeting was an exhibition of astronomical apparatus, photographs, spectra, etc., arranged by the French National Committee with the co-operation of observatories and optical firms. This was open throughout the meeting and proved most successful. It was organised by the Comte A. de la Baume Pluvinel and M. Jules Baillaud. The latter acted jointly with M. A. Lambert as secretaries of the local committee, and to their unstinted efforts the success of the meeting was mostly due.

At the final meeting of the general assembly the following were elected as the executive committee to hold office until the next general assembly, to be held at Stockholm in 1938 : President : M. Esclangon (France); Vice-Presidents : Dr. Adams (U.S.A.), Prof. Banachiewicz (Poland), Prof. Bergstrand (Sweden), Prof. Bianchi (Italy) and Dr. Spencer Jones (Great Britain); General Secretary : Dr. Oort (Netherlands).

\section{Zooplankton of the Great Barrier Reef}

\begin{abstract}
A NOTABLE addition to the reports of the Great A Barrier Reef Expedition has recently appeared*. In the first part the validity of the collecting methods is discussed, the effect of the transparency of the water and the relative abundance and composition of the zooplankton, with a comparison of temporary and holoplanktonic animals. Oblique hauls were made to ensure large enough catches to give significant results, and vertical hauls through a water column of known depth were made to give information directly comparable with data obtained elsewhere. The methods used are shown to be reliable.

* British Museum (Natural History). Great Barrier Reef Expedition, 1928-29. Scientific Reports, Vol. 2, No. 6: The Zooplankton. (2): The Composition of the Zooplankton of the Barrier Reef Lagoon, by F. S. Russell and J. S. Colman; (3): A Comparison of the Abundance of Zooplankton in the Barrier Reef Lagoon with that of some Regions in Northern European Waters, by F. S. Russell. Pp. 159-
\end{abstract}

Curves of the average catches of all animals for each month in the coarse silk net oblique and vertical hauls at a position three miles east of Low Isles in the Barrier Reef Lagoon agree well on the whole. Taking the copepods alone, the agreement is even closer, the month of January being the only one where there is any considerable disagreement, when many more copepods occurred in the vertical hauls. Daylight samples compare with those taken by night in a very similar way to those taken at Plymouth. The transparency of the water, which has already been shown to have a direct connexion with the wind (Orr, Vol. 2, No. 3 of these Reports), has a considerable effect on the numbers of animals caught, the curves of abundance in both oblique and vertical hauls, of copepods, decapod larvæ and chætognaths following closely the curve of transparency. There seems to be practically no seasonal variation in 